\title{
Dark side of Molecular Techniques: How to fix it ?
}

\author{
Vikash Bhardwaj \\ Molecular Biology and Genetics Domain, Lovely Professional University, Punjab 144411, India; \\ vikashbhardwaj@gmail.com
}

\begin{abstract}
Many fundamental molecular techniques (PCR, Microarray, Southern and northern hybridization, siRNA, CRISPR/Cas9 etc,) developed so far shows errors. I wish to highlight these molecular techniques are developed on basis of Watson-Crick DNA model, ignoring the concept of parallel stranded DNA. Through this opinion article I wish to highlight specificity and accuracy of these molecular techniques can be enhanced by considering both parallel and anti-parallel hybridization of DNA. Hopefully my views will also solve issue of irreproducibility in life science research.
\end{abstract}

Keywords: parallel DNA; antiparallel DNA; PCR; CRISPR; nucleic acid hybridization; microarray; siRNA

\section{Introduction}

Literal meaning of science is 'to know' and none of us in this world want to know false facts. Everyone is searching the ultimate truth, the knowledge which can be applied for betterment of society. Today worldwide research in field of biology, not merely depends on "Hypothesis" only but it is more technology driven. After the discovery of molecular structure of DNA (Watson-Crick double helical model), there has been a lot of progress in field of molecular biology and many molecular techniques (PCR, Microarray, Southern and northern hybridization, siRNA, CRISPR/Cas9 etc) have been developed. Today these molecular techniques are widely used to study fundamental principles of life and many research papers published in life science fields are based on these molecular techniques. In 2012, the biotechnology company Amgen reported that only $10 \%$ of researches published in top journals by world best labs are reproducible (1). It is an alarming situation that $\$ 28$ billion dollar is wasted in life science field every year in USA alone (2). What is total wastage world-wide? In a recent survey on reproducibility in various fields, "More than $70 \%$ of researchers reported that they have tried and failed to reproduce another scientist's experiments, and more than half have failed to reproduce their own experiments. $52 \%$ of those surveyed agreed that there is a significant 'crisis' of reproducibility, less than 31\% think that failure to reproduce published results means that the result is probably wrong"(3). It clearly indicates that now we are moving into dark phases. As it is difficult for a common man to search things in darkness, it will be difficult for scientists to search true findings among false ones. You must have heard the story in which a group of blind men when investigated an elephant comes to different opinions after touching the elephant (4). Every scientific finding is based on previously published literatures which are commonly cited as reference within an article. If we consider, $90 \%$ of research articles are irreproducible then there will be a very high probability that every finding in life science research is discussed/based on much irreproducible research papers directly or indirectly. Whatever knowledge we generate today, have to be used by next generation of young scientists. Will it not confuse many young scientists for next many hundred years? Will it not make situations of young scientists as equal to blind men? Many labs are publishing lot of findings. It will become difficult to find absolute novel usable research among large number of research papers. In last few years, Phase II success rate for new development projects has decreased by $10 \%$ and this will definitely increase the cost of new drugs and decrease the trust of the public, Government and funding agencies in scientific activities (5). I wish to highlight one reason behind this is that many molecular techniques shows errors and there is a little progress in making them error free. You may read various published reports which have shown that various molecular techniques like Microarray $(6,7,8,9,10)$, siRNA $(11,12,13,14,15,16)$, CRISPER $(17,18,19,20)$ 
shows errors. Even you must have experienced non-specific amplification in a PCR reaction and nonspecific hybridization in Southern and northern hybridization experiments.

Recently We have raised an issue that much of research published in molecular biology field is based on 'Watson-Crick' anti-parallel DNA model (21) ignoring the concept of parallel stranded DNA model $(22,23)$. Even various molecular techniques developed so far are based on antiparallel DNA model. We strongly believe that errors reported in various bio-techniques can be resolved by considering both parallel and anti-parallel hybridization of DNA (24). Recently, we have developed a PD-PCR technique by applying the knowledge of both parallel and anti-parallel hybridization of DNA (25). In 2008, Lestienne et al. has also reported that Triple helix primer (THP) bounded to the duplex DNA in a parallel orientation can initiate DNA synthesis (26). In different studies, it has been already reported that Southern hybridization reaction can be performed using parallel complementary probe and gene silencing can be applied using parallel complementary RNA $(27,28,29)$. There are no drastic differences in nearest neighbour base pairs interactions between parallel and antiparallel DNA having mixed AT/GC composition. In parallel stranded DNA, both A-T and G-C pairs with two hydrogen bonds via reversed Watson-Crick base pairing rule (30). The minor groove becomes shallow and wide in parallel DNA. Thus, parallel complementary DNA contains groves of equal size in contrast to dissimilar grooves (major and minor grooves) found in antiparallel B-form of DNA. Various DNA binding drugs and dyes have been reported to show different molecular interaction with parallel stranded DNA in comparison to the antiparallel stranded DNA $(31,32,33)$. In 2000, LeProust et al studied "GAA GAA G AAG AAG" and its complementary "CTT CTT C TTC TTC" mirror repeats sequence. Their results indicated that such type of sequences have a possibility to form triplex DNA, antiparallel duplex DNA and Parallel duplex DNA based on pH as confirmed by various physical, chemical and enzymatic probing methods. When such duplex mirror sequences were subjected to electrophoresis at $\mathrm{pH}$ 8.3, they separated into two bands. The faster migrating band (FM) corresponded to parallel DNA while the slower one represented antiparallel duplex DNA (34). In 1988, RamSing and Jovin have also reported that parallel duplex sequence migrates faster than antiparallel duplex (22).

In sum, complementary in DNA can be defined by two ways "Parallel Complementary" and "Antiparallel Complementary". In Current scenario, there is a need to develop molecular techniques (siRNA technology, Microarray, CRISPER genome editing etc) free of non-specific reactions then only we will be able to know root causes of various diseases. There is a science behind non-specific reactions in various molecular techniques. If we know the reason behind errors then only we can rectify it. We strongly believe applying knowledge by considering all possibilities (parallel and antiparallel hybridization of DNA, Non-watson Crick pairing rules) will minimize errors in molecular techniques and will take us towards a new light which will make us more reproducible in life science research. There will be more progress in life science if we come out of dark phase in lesser time and devote more time in light phase of life science. Molecular techniques without errors will increase reproducibility in research worldwide.

"Science is based on experiment, on a willingness to challenge old dogma, on an openness to see the universe as it really is. Accordingly, science sometimes requires courage- at the very least the courage to question the conventional wisdom" Carl Sagan

Competing interests: The author declare no competing interests

References

1. Begley, C. Glenn, and Lee M. Ellis. 2012. Drug development: Raise standards for preclinical cancer research." Nature. 483: 531-533. 
2. Freedman, Leonard P., Iain M. Cockburn, and Timothy S. Simcoe.2015.The economics of reproducibility in preclinical research." PLoS Biol 13.6: e1002165.

3. http://www.nature.com/news/1-500-scientists-lift-the-lid-on-reproducibility-1.19970

4. http://www.constitution.org/col/blind_men.htm

5. Arrowsmith J: Trial watch: Phase II failures: 2008-2010. 2011. Nat Rev Drug Discov. 10: 328-329

6. Kothapalli R, Yoder SJ, Mane S, et al. 2002. Microarray results: how accurate are they? BMC Bioinformatics. 3: 22

7. Draghici S, Khatri P, Eklund AC, et al. 2006. Reliability and reproducibility issues in DNA microarray measurements. Trends Genet. 22: 101-109.

8. Irizarry RA, Warren D, Spencer F, et al. 2005. Multiple-laboratory comparison of microarray platforms. Nat Methods. 2: 345-350.

9. $\mathrm{Xu} \mathrm{J}$, Deng X, Chan V, et al. 2007. Variability of DNA microarray gene expression profiles in cultured rat primary hepatocytes. Gene Regul Syst Bio. 1: 235-249

10. Koltai H, Weingarten-Baror C. 2008. Specificity of DNA microarray hybridization: characterization, effectors and approaches for data correction. Nucleic Acids Res. 36: 23952405.

11. Jackson AL, Linsley PS. 2004. Noise amidst the silence: off-target effects of siRNAs? Trends Genet. 20: 521-524.

12. Jackson AL, Bartz SR, Schelter J, et al. 2003. Expression profiling reveals off-target gene regulation by RNAi. Nat Biotechnology. 21: 635-637.

13. Scacheri PC, Rozenblatt-Rosen O, Caplen NJ, et al. 2004. Short interfering RNAs can induce unexpected and divergent changes in the levels of untargeted proteins in mammalian cells. Proc Natl Acad Sci U S A. 101: 1892-1897.

14. Tschuch C, Schulz A, Pscherer A, et al. 2008. Off-target effects of siRNA specific for GFP. BMC Mol Biol. 9: 60.

15. Jackson AL, Burchard J, Schelter J, et al. 2006. Widespread siRNA "off-target" transcript silencing mediated by seed region sequence complementarity. RNA.12:1179-1187.

16. Gumienny R, Zavolan M. 2015. Accurate transcriptome-wide prediction of microRNA targets and small interfering RNA off-targets with MIRZA-G. Nucleic Acids Res. 43:1380-1391.

17. Kim, Daesik, et al. 2015. "Digenome-seq: genome-wide profiling of CRISPR-Cas9 off-target effects in human cells." Nature methods 12: 237-243.

18. Fu Y, Foden JA, Khayter C, Maeder ML, Reyon D, Joung JK, Sander JD 2013. High-frequency off-target mutagenesis induced by CRISPR-Cas nucleases in human cells. Nat Biotechnology 31: 822-826

19. Hsu PD, Scott DA, Weinstein JA, Ran FA, Konermann S, Agarwala V, Li Y, Fine EJ, Wu X, Shalem O, et al. 2013. DNA targeting specificity of RNA-guided Cas9 nucleases. Nat Biotechnology 31: 827-832

20. Pattanayak V, Lin S, Guilinger JP, Ma E, Doudna JA, Liu DR. 2013. High-throughput profiling of off-target DNA cleavage reveals RNA-programmed Cas9 nuclease specificity. Nat Biotechnology 31: 839-843

21. Watson JD, Crick FH. 1953. Molecular structure of nucleic acids; a structure for deoxyribose nucleic acid. Nature. 171: 737-738.

22. Ramsing NB, Jovin TM. 1988. Parallel stranded duplex DNA. Nucleic Acids Res. 16: 6659-6676.

23. van de Sande JH, Ramsing NB, Germann MW, et al. 1988. Parallel stranded DNA. Science. 241: $551-557$

24. Bhardwaj V. 2015. Villain of Molecular Biology: Why are we not reproducible in research? F1000Research. 4: 438

25. Bhardwaj V, Sharma K. 2014. Parallel DNA polymerase chain reaction: Synthesis of two different PCR products from a DNA template. F1000Research. 3: 320 
26. Lestienne PP, Boudsocq F, Bonnet JE. 2008. Initiation of DNA Replication by a Third Parallel DNA Strand Bound in a Triple-Helix Manner Leads to Strand Invasion. Biochemistry. 47: 5689-5698

27. Tchurikov NA, Shchyolkina AK, Borissova OF, et al.1992. Southern molecular hybridization experiments with parallel complementary DNA probes. FEBS Lett. 297: 233-6

28. Tchurikov NA, Chistyakova LG, Zavilgelsky GB, et al. 2000. Gene-specific silencing by expression of parallel complementary RNA in Escherichia coli. J Biol Chem. 275: 26523-9.

29. Liu YS, Zhang YQ, Yang LX, et al. 2009. Gene-specific silencing induced by parallel complementary RNA in Pseudomonas aeruginosa. Biotechnol Lett. 31: 1571-1575

30. Shchyolkina, A. K., Borisova, O. F., Livshits, M. A. \& Jovin, T. M. 2003. Parallel-Stranded DNA with Natural Base Sequences. Mol. Biol. 37: 223-231

31. Yang, X., Sugiyama, H., Ikeda, S., Saito, I. \& Wang, A. H. 1998. Structural Studies of a Stable Parallel-Stranded DNA Duplex Incorporating Isoguanine: Cytosine and Isocytosine: Guanine Basepairs by nuclear magnetic resonance spectroscopy. Biophysical journal. 75: 11631171

32. Seela, F., \& Wei, C. 1997. Oligonucleotides containing consecutive 2'deoxyisoguanosine residues: synthesis, duplexes with parallel chain orientation, and aggregation. Helvetica chimica acta, 80: 73-85

33. Li, H., Peng, X., Leonard, P., \& Seela, F. 2006. Binding of actinomycin C 1 (D) and actinomin to base-modified oligonucleotide duplexes with parallel chain orientation. Bioorganic $\mathcal{E}$ medicinal chemistry, 14: 4089-4100

34. LeProust, E. M., Pearso, C. E., Sinden, R. R. \& Gao, X. 2000. Unexpected formation of parallel duplex in GAA and TTC trinucleotide repeats of Friedreich's ataxia. J. Mol. Biol. 302: 10631080 . 